\title{
Self-Medication Practice among Pharmacists in UAE
}

\author{
Suleiman I. Sharif*, Laila M. T. Bugaighis, Rubian S. Sharif \\ Department of Pharmacy Practice \& Pharmacotherapeutics, College of Pharmacy, University of Sharjah, \\ Sharjah, UAE \\ Email: $\underline{\text { sharifsi@sharjah.ac.ae }}$
}

Received 7 August 2015; accepted 7 September 2015; published 10 September 2015

Copyright (C) 2015 by authors and Scientific Research Publishing Inc.

This work is licensed under the Creative Commons Attribution International License (CC BY). http://creativecommons.org/licenses/by/4.0/

(c) (i) Open Access

\begin{abstract}
Objectives: The purpose of this study was to determine the incidence of self-medication behavior among practicing pharmacists in UAE. Methods: This anonymous questionnaire-based study was conducted between October and December 2014, using a pre-piloted questionnaire. The questionnaire was distributed to a total of 168 pharmacists. Data were analyzed using SPSS and results were expressed as number of respondents and percentage of total participants. Results: The questionnaire was completed by 149 pharmacists, and response rate was $89 \%$ with $53 \%$ of respondents being Arabs. Out of the 149 pharmacists respondents, 71 (47.7\%) are males, and 78 (52.3\%) are females. The mean age among pharmacists was 28. Large number of pharmacists practiced self-medication (96.6\%). The majority obtained their medication from pharmacies (92.6\%). Most respondents were aware of bacterial resistance and the concept of rational drug use. However, 69 $(43 \%)$ of pharmacists had used antibiotics without consultation in the past year. The main reasons for self-medication were that their health problem is not serious $(42 \%)$ and their knowledge on drugs and diseases helps (31\%). Reasons against self-medication included risk of misdiagnosis of illness and risk of adverse effects. Pharmacists tended to seek medical consultation mostly in case of symptoms lasting for more than one week or when symptoms were worsening. Discussion: The frequency of self-medication among pharmacists is high. The professional exposure to drugs and knowledge of illness and treatment choice remains the fundamental contributors to self-medication practice among pharmacists. Interventions to promote rational self-medication among practicing pharmacists are required and pharmacists must be encouraged to enter the patient role.
\end{abstract}

\section{Keywords}

Self-Medication, Over-The-Counter, Antibiotics, Pharmacists

\footnotetext{
${ }^{*}$ Corresponding author.
} 


\section{Introduction}

Self-care refers to actions and attitudes which are practiced by people to help them contribute to the maintenance of their well-being and personal health. Self-medication is often described as the medical spontaneous use of prescription and Over-The-Counter (OTC) drugs to treat self-recognized disorders, symptoms or minor illnesses without the consultation of a physician either for diagnosis, treatment or monitoring [1]-[3]. Several studies which were done on self-medication revealed that it was a common practice, especially in countries where there were no strict regulations and prescription drugs were freely dispensed [2] [4]. Self-medication behavior has become a global trend that has been internationally reported as being on rise and can have positive as well as negative impacts [5]. It has been noticed that the increased trend of self-medication practice is not only detected in countries with advanced economy but also in developing countries [6].

Responsible self-care using medications can have positive effects on the individual and the health care system when practiced correctly [2]. However, this practice requires a certain level of knowledge [7]. Self-medication if practiced appropriately can help in the prevention and the treatment of signs and symptoms which do not require a doctor's visit, as well as it can enable those patients with chronic conditions to take responsibility to control their own condition [8]. Also, rational self-care practice can decrease the pressure on the medical services, where health care personnel are inadequate [8]. Furthermore, it can increase health awareness among people and allow them to build confidence and take charge to manage their own health [2]. It has been reported that in United Arab Emirates, like the rest of the world, people tend to go for self-medication for many reasons which include the high fee cost of medical consultation, lack of time, long hours of waiting at the physician's clinic, lack of trust in the physicians' medical knowledge, previous experience with the medical condition and its drug management, and the lack or the unavailability of near health facilities [4].

On the other hand, self-care can have drawbacks when inappropriately practiced. Although the efficacy and the safety of OTC drugs are scientifically and clinically proven and are usually meant for self-medication, the improper use or abuse of such drugs can cause serious consequences in different types of populations [9]. In addition, irrational self-medication can lead to the possibility of serious adverse effects, drug interactions, drug dependence and poly pharmacy [2] [10].

Studies have shown that self-medication patterns vary among different populations and are usually influenced by many factors. These include, among others, age, gender, income, education level, medical knowledge, availability of drugs, and exposure to advertisements and perception of illnesses [3]. It has been shown that self-medication is much more common among physicians, nurse, pharmacists and medical students than among the general population [7]. There is no sector in the healthcare community which is immune to drug abuse or misuse [11]. Physicians and pharmacists are considered to be the worst offenders as they have an easy access to medications, have medical background and high self-confidence [9] [11]. The present study was undertaken to investigate the pattern of self-medication among practicing pharmacists in United Arab Emirates (UAE).

\section{Methods}

This anonymous questionnaire-based study was conducted between October and December 2014 and participants were asked to report self-medication in the previous year using a pre-validated questionnaire. This questionnaire was initially piloted on a sample of 10 pharmacists. The purpose of the pre-validation step was to test face validity in order to reduce technical and structural errors, asses the time needed for completion of the questionnaire and the general attitude towards such survey. The recommendations of the pharmacists were taken into consideration and the questionnaire was adjusted accordingly.

The study was approved by the Research and Ethics Committee of the Colleges of Medicine and Health Sciences, University of Sharjah, United Arab Emirates. The questionnaire was in English and it consisted of both open- and closed-ended items which were modified from questionnaires used in our previous studies [4].

The study population included pharmacists working in community pharmacies, outpatient hospital pharmacies or pharmacies available at clinics. The questionnaire was distributed to a total of 168 pharmacists. The surveys were spread to pharmacies in Sharjah (21 pharmacies and 2 clinics) and Dubai (35 pharmacies, 2 clinics and 3 hospitals).

The questionnaire consisted of three sections. The first section included questions covering demographic information such as age, gender, nationality, academic/professional qualifications and experience of the practicing pharmacist. The second section consisted of questions about self-medication and participants were asked to re- 
port the use of prescription and/or OTC drugs for self-treatment during the past year. This section included questions about the type of self-medications used, duration of use, source of drugs, and use of antibiotics, reasons for and against self-medication and reasons for seeking medical consultation. Certain definitions and terms were explained to the participants to understand the purpose of the study. Self-Medication was well-defined as the use of over the counter medications, prescription drugs, traditional treatments or any substance which was used to treat a condition or a symptom without consulting a physician.

The survey was descriptive and results were analyzed and expressed as number of respondents and percentage of total participants in each group. Some questions had multiple options to choose from; therefore the sum total of percentages is not always $100 \%$.

\section{Results}

The questionnaire was completed by 149 pharmacists giving a response rate of $88.7 \%$. The respondents included 71 (47.7\%) males, and 78 (52.3\%) females. Participants were of different nationalities whereas Arabs comprised more than half of the sample (79.2\%) with $11.9 \%$ of them Emirati nationals and the rest expatriates (Table 1). The mean age of the respondents was 28 years (range 22 - 60).

Self-medication practice, duration of use, source of medicines and self-use of antibiotics are shown in Table 2. Large number of pharmacists (96.6\%) practiced self-medication. The majority 138 (92.6\%) obtained their medication from pharmacies and used it for one week $(113,75.8 \%)$. Antibiotics were used for self-medication by 69 (46.3\%) pharmacists. The majority of participants (135, 90.6\%) and (126, 84.6\%) were aware of the possibility of the development of bacterial resistance and the concept of rational drug use respectively. As shown in Table 3, the most common reasons for self-medication were "health problem is not serious" (61, 42.4\%), "knowledge on drugs and diseases helps" (45, 31.3\%), and "having no health insurance" (16, 11.1\%). Table 4 shows the common reasons against self-medication. These included "risk of misdiagnosis of illness" (79, 53\%), "risk of adverse effect” (77, 51.7\%), and "risk of using wrong medication” (62, 41.6\%). Reasons for seeking medical consultation are also shown in Table 4 and included, among others, "symptoms are lasting for more than one week” (79, 54.9\%), “symptoms are worsening” (52, 36.1\%), and “presence of severe pain” (40, 27.8\%).

Figure 1 shows the most common over-the-counter drugs used for self-medication. Ranked first were analgesics followed by vitamins, antihistaminics, antacids and nasal decongestants. The most frequent symptoms for which self-medication were practiced included headache, cough, fever, cold and flu and back pain (Figure 2). The most common conditions for which pharmacists used antibiotics for self-medication are shown in Figure 3.

\section{Discussion}

In the present study the prevalence of self-medication is rather high. Such prevalence is reminiscent to the trend in Malaysian pharmacists [12]. The respondents who practiced self-medication were aged between 22 - 60 years. From the irregularity in the age distribution of the respondents and the prevalence rate of self-medication, it is clear that there is no significant association between the age of respondents and prevalence of self-medication

\begin{tabular}{ccc} 
Table 1. Socio-demographic data of pharmacists practicing self-medication. \\
\hline Variable & Males & Frequency (\%) n = 149 \\
\hline Gender & females & $71(47.7 \%)$ \\
Nationality & Arabs & $78(52.3 \%)$ \\
& Non Arabs & $118(79.2 \%)$ \\
& Emirati & $31(20.8 \%)$ \\
& Non Emirati & $14(11.9 \%)$ \\
Educational Level & Bachelor of Pharmacy & $104(88.1 \%)$ \\
& Masters of Pharmacy & $135(90.6 \%)$ \\
& Ph.D. & $13(8.7 \%)$ \\
\end{tabular}


Table 2. Practice of self-medication among pharmacists.

\begin{tabular}{ccc}
\hline Practice & & Frequency (\%) n = 149 \\
\hline Did you use self-medication in the past year? & Yes & 144 (96.6\%) \\
Where was the medication obtained from? & No & $5(3.4 \%)$ \\
Duration of self-medication & Pharmacy & $138(92.6)$ \\
& Street Market & $3(2.1 \%)$ \\
& Herbal Store & $2(1.4 \%)$ \\
Antibiotic obtained as self-medication & 1 week & $1(0.7 \%)$ \\
& 2 weeks & $113(75.8 \%)$ \\
Duration of use & 1 month & $3(2 \%)$ \\
& $>1$ month & $12(8.1 \%)$ \\
Awareness of rational drug use & Yes & $69(46.3 \%)$ \\
& No & $80(53.7 \%)$ \\
& 1 week & $135(90.6 \%)$ \\
& 2 weeks & $14(9.4 \%)$ \\
\hline
\end{tabular}

Table 3. Reasons for self-medication among pharmacists.

\begin{tabular}{cc}
\hline Reasons for self-medication & Frequency (\%) n = 149 \\
Health problem is not serious & $61(42.4 \%)$ \\
knowledge on drugs and disease helps & $45(31.3 \%)$ \\
I don't have insurance & $16(11.1 \%)$ \\
Avoidance of waiting long time at clinics & $13(9 \%)$ \\
Physicians advice of self-management & $9(6.3 \%)$ \\
Suggestion of a relative/friend & $3(2.1 \%)$ \\
Self-need to play an active role & $8(5.6 \%)$ \\
Learning opportunity & $7(4.9 \%$ \\
I do not trust my physician & $6(4.2 \%)$ \\
Physician prescription was not effective & $3(2.1 \%)$ \\
Embarrassed of discussing own symptoms & $1(0.7 \%)$ \\
High cost of medical consultation & $0(0 \%)$ \\
Seeking quick relief & $0(0 \%)$
\end{tabular}

among practicing pharmacists. It has been claimed that the incidence of self-medication is dependent on how the question was constructed in the questionnaire with respect to past or present self-medication practice [13]. Our present and earlier [4] results do not support such claim as in both studies, we enquired about self-medication throughout last year and still the prevalence is high.

Among healthcare professionals, Pharmacists are with the greatest access to medications and also have adequate knowledge of prescription and OTC drugs and their use in the treatment of various conditions. These factors increase the potential of self-medication [9]. In the present study, the number of pharmacists with Ph.D., 


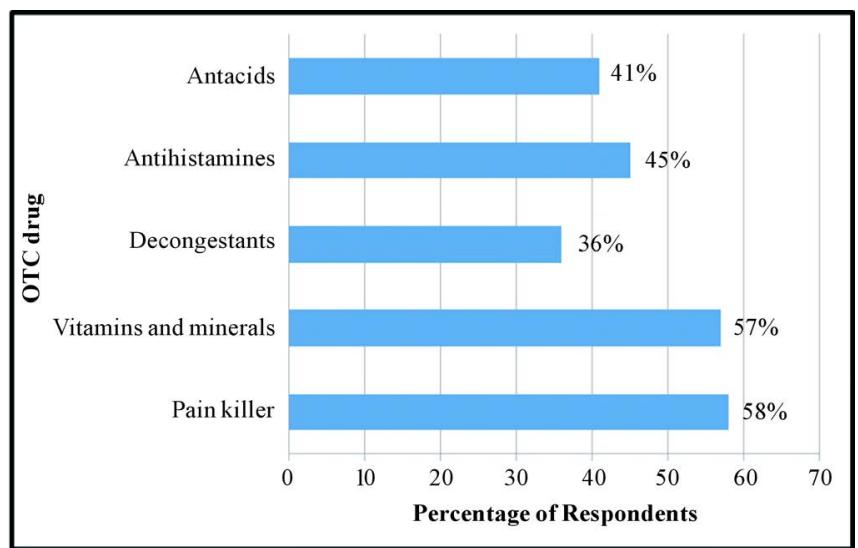

Figure 1. The most common over-the-counter (OTC) drugs used for self-medication by pharmacists.

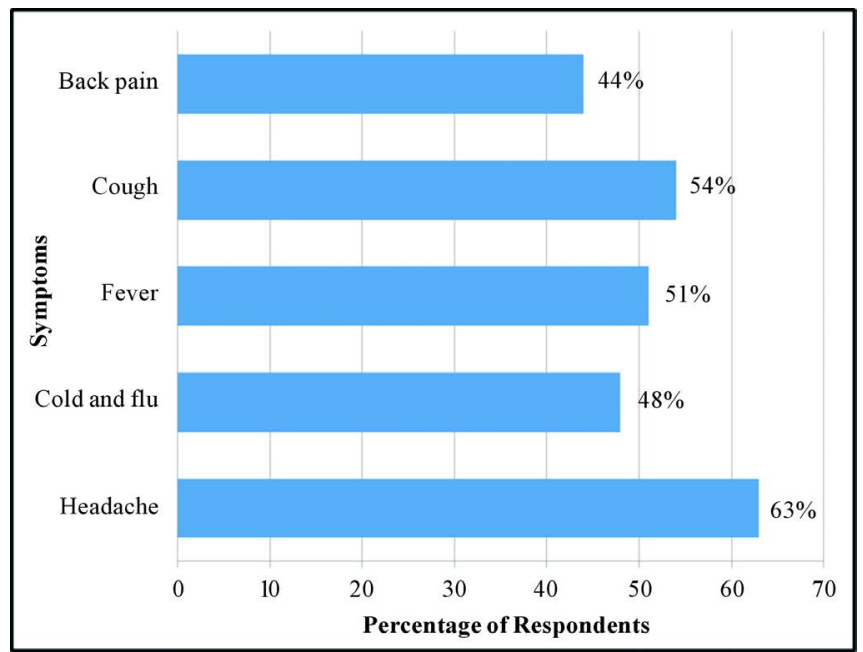

Figure 2. The most common conditions self-medicated by pharmacists.

Table 4. Reasons against self-medication and for seeking medical consultation among pharmacists practicing self-medication.

\begin{tabular}{lcc}
\hline & Reason & Frequency (\%) n = 149 \\
\hline Reason against self-medication & Risk of adverse effects & $77(51.7 \%)$ \\
$62(41.6 \%)$ & $79(53 \%)$ \\
& Risk of using wrong medication & $46(30.9 \%)$ \\
Reason for seeking medical consultation & Risk of misdiagnosis of illness & $44(29.5)$ \\
& Risk of drug interaction & $46(30.9 \%)$ \\
& Risk of drug abuse and dependence & $79(54.9 \%)$ \\
$52(36.1 \%)$ \\
Risk of progression of case & $40(27.8 \%)$ \\
& Symptoms last for more than one week & $34(23.6 \%)$ \\
& Presence of severe pain & $4(2.8 \%)$ \\
\end{tabular}




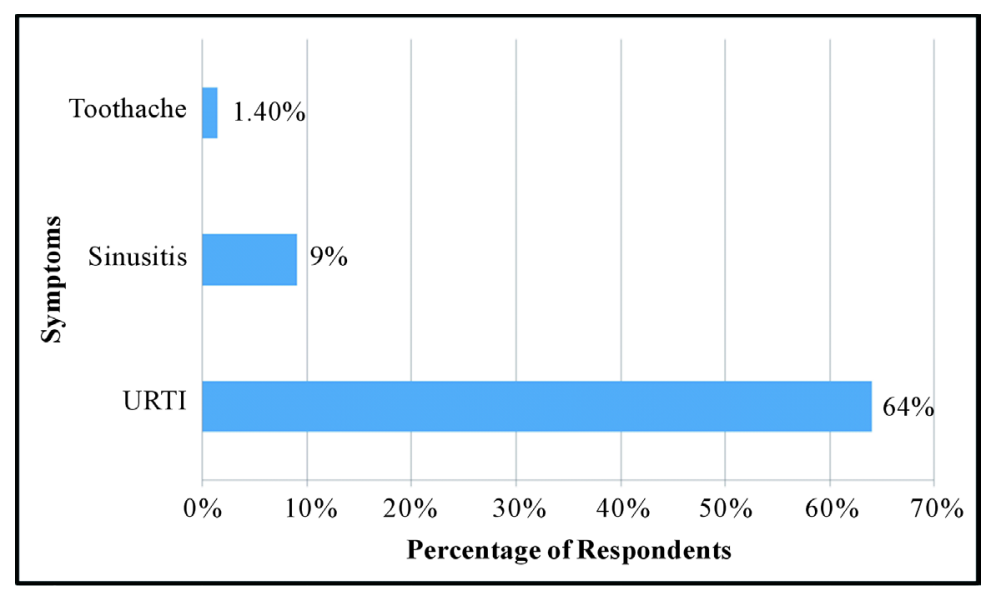

Figure 3. The most common conditions for which pharmacists self-medicated with.

master or diploma degrees is rather small to run any valid comparison with the rest of respondents who have a first degree. It has been claimed that there is no relation between the prevalence of self-medication and academic qualification [12]. However, others [14] [15] observed that people with higher level of education tend to self-medicate more frequently. The reason could be attributed to that, the higher the knowledge about medicines the greater is the personal confidence of pharmacists in making decisions about their own health. It is also an assumed fact that the level of qualification is directly associated with the medication knowledge possessed and the familiarity with the treatment options. As presented in this study, it is worth pointing out that we did not enquire about the frequency of self-medication and all respondents regardless of their qualifications self-medicated with drugs.

The main reason for self-medication was "health problem is not serious" followed by "knowledge on drugs and diseases helps". This is reminiscent to reasons forwarded by Malaysian pharmacists [12]. Our results show that only small number (11.1\%) of respondents self-medicated because they do not have medical insurance. Fortunately enough, all of them used only OTC drugs although these cannot be always without possible adverse effects. Considering the low salary of pharmacists practicing in community pharmacies, self-medication would certainly be a hazardous practice in case of serious illness that requires the use of prescription drugs.

Issues pertaining to time saving and avoidance of long waiting time at clinics, though scored low (9\%) in this study, they have also been observed in previous studies [12] [16] [17]. In these later studies, long working hours were among other factors that predispose pharmacists and other healthcare professionals to self-medication.

On the other hand, Risk of misdiagnosing the condition and adverse effects were ranked as the main reasons deterring respondents from practicing self-medication while risks of using wrong medication, progression of case, and drug interaction were ranked second. Results of the present study further indicated that a large number of the respondents had more than 6 years of professional experience and also have the high prevalence of self-medication. However, this does not indicate that the prevalence of self-medication increases with the increase in professional experience of respondents since their prevalence was not significantly different from that of the respondents with less than 6 years of experience. Professional experience may be directly associated with the drug knowledge and familiarity with therapeutic options.

Consequences of irrational self-medication among pharmacists may prove severe if safety measurements are not considered. Medication misuse and abuse associated with self-medication by pharmacists had been shown to be major risk factors for medical malpractice and negligence, lawsuits along with the development of physical and psychological illness [18].

The main source of obtaining medication was the pharmacy and only very few respondents obtained their medications from other sources including street market, herbal stores and relatives or friends. This result supports the results of earlier studies [19] [20]. Alarmingly, 46\% of respondents obtained antibiotics for self-medication without a physician consultation despite the fact that the majority of respondents were aware of the concept of rational drug use (126, 84.6\%) and the risk of development of bacterial resistance (135 (90.6\%) consequent to misuse. Such a trend is probably enhanced by the fact that antibiotics, like other most prescription drugs, can still be obtained without a prescription regardless of the strict regulations of health authorities in the UAE. 
This issue requires more attention of health authorities through interventions directed to increase awareness of not only practicing pharmacists but also the general public to the rational use of antibiotics.

In the present study, the major indication for self-medication was headache (63\%) followed by cold and flu (54\%) and fever and chills (51\%). This order corresponds with previous reports [21] that most drugs used for self-medication were drugs for pain and respiratory system. Association of the European Self-Medication Industry has listed common diseases in self-medication as pain, allergy, colds, sore throats, coughs and diarrhea [22]. OTC drugs such as pain killers, and vitamins and minerals recorded high rates in self-medication. Easy availability of OTC drugs has been suggested [23] as a principal factor contributing to the high rate of self-medication with such drugs.

Antibiotics are susceptible to the risk of misuse and yet they are often exposed to high rate of self-medication practices [4] [24]. In contrast to results in Malaysia [12] on self-medication with antibiotics, a high rate of antibiotics was observed in the present as well as previous studies [25] [26]. Moreover, our results illustrated that the main indication for antibiotics use was upper respiratory tract infection. This is in accordance with the results of other studies [24] [27] that the main indication for self-medication with antibiotics was respiratory problems such as common cold and sore throat. Such indication are usually of viral origin [4] and efforts must be enhanced to increase the awareness of not only health professional but also the public to rational drug use and consequences of antibiotic misuse.

\section{Conclusion}

The prevalence of self-medication among practicing pharmacists in UAE was high. Knowledge of pharmacists of reasons for and against self-medication seems appropriate. The professional exposure to drugs, knowledge of their illness and treatment choice remains the fundamental contributors to self-medication practice among pharmacists. More efforts are needed to promote responsible self-medication. Inclusion in the pharmacy curricula of topics/courses dealing with rational drug and antibiotic use and general aspects of self-medication may be useful. Like any other person, pharmacists must accept and be encouraged to assume their role as patients when their health is compromised. In addition, health authorities should practice more strict control over community pharmacists with regard to dispensing prescription drugs.

\section{Acknowledgements}

The authors are greatly indebted to all pharmacists who participated in the study.

\section{Limitation of the Study}

As many pharmacists declined to participate in this anonymous survey, the sample size was rather small. The study focused only on pharmacists, future studies may include other healthcare professionals.

\section{Conflict of Interest}

The authors declare that there is no conflict of interest.

\section{References}

[1] Afolabi, A.O. (2008) Factors Influencing the Pattern of Self-Medication in an Adult Nigerian Population. Annals of African Medicine, 7, 120-127. http://dx.doi.org/10.4103/1596-3519.55666

[2] Hughes, C.M., McElnay, J.C. and Fleming, G.F. (2001) Benefits and Risks of Self-Medication. Drug Safety, 24, 1027-1037. http://dx.doi.org/10.2165/00002018-200124140-00002

[3] Montastruc, J.L., Bagheri, H., Geraud, T., et al. (1979) Pharmacovigilance of Self-Medication. Therapy, 52, $105-110$.

[4] Sharif, S.I., Ibrahim, H.M.O., Mousli, L. and Waisi, R. (2012) Evaluation of Self-Medication among Pharmacy Students. American Journal of Pharmacology and Toxicology, 7, 135-140. http://dx.doi.org/10.3844/ajptsp.2012.135.140

[5] Cindy, L.K., Maxwell, H.W. and Clarke, M. A. (1989) Survey on the Use of Self-Medication over a Period of Two Weeks. Hong Kong Journal, 11, 371-375.

[6] Shankar, P.R., Partha, P. and Shenoy, N. (2002) Self-Medication and Non-Doctor Prescription Practices in Pokhara Valley, Western Nepal. A Questionnaire Based Study. BMC Family Practice, 3, 17. 
http://dx.doi.org/10.1186/1471-2296-3-17

[7] Aljinovic-Vucic, V., Trkulja, V. and Lackovic, Z. (2005) Content of Home Pharmacies and Self-Medication Practices in Households of Pharmacy and Medical Students in Zagreb, Croatia: Findings in 2001 with a Reference to 1977. Croatian Medical Journal, 46, 74-80.

[8] Jain, S., Malvi, R. and Purviya, K.J. (2011) Concept of Self-Medication: A Review. International Journal of Pharmaceutical \& Biological Archive, 2, 831-836.

[9] Balbisi, E.A. and Ambizas, E.M. (2005) Self-Prescribing of Non-Controlled Substances among Pharmacists. American Journal of Health-System Pharmacy, 62, 2508-2511. http://dx.doi.org/10.2146/ajhp050007

[10] Sarahroodi, S., Arzi, A., Swalha, A.F. and Ashtranezhad, A. (2010) Antibiotic Self-Medication among Southern Iranian University Students. Indian Journal of Pharmacology, 6, 48-52.

[11] Dabney, D.A. (2001) Onset of Illegal Use of Mind-Altering or Potentially Addictive Prescription Drugs among Pharmacist. Journal of American Pharmacists Association, 4, 392-400.

[12] Ali, A., Kai, K., Keat, C. and Dhanaraj, S. (2012) Self-Medication Practices among Health Care Professionals in a Private University, Malaysia. International Current Pharmaceutical Journal, 1, 302-310. http://dx.doi.org/10.3329/icpj.v1i10.11846

[13] Almasdy, D. and Sharrif, A. (2011) Self-Medication Practice with Nonprescription Medication among University Students: A Review of the Literature. Archives of Pharmacy Practice, 2, 95-100.

[14] Barros, A.R.R., Griep, R.H. and Rotenberg. L. (2009) Selfmedication among Nursing Workers from Public Hospitals. Revista Latino-Americana de Enfermagem, 17, 1015-1022. http://dx.doi.org/10.1590/S0104-11692009000600014

[15] Figueiras, A., Caamaño, F. and Gestal-Otero, J.J. (2000) Sociodemographic Factors Related to Self-Medication in Spain. European Journal of Epidemiology, 16, 19-26. http://dx.doi.org/10.1023/A:1007608702063

[16] Rosen, I.M., Christie, J.D., Bellini, L.M. and Asch, D.A. (2000) Health and Health Care among House Staff in Four U.S. Internal Medicine Residency Programs. Journal of General Internal Medicine, 15, 116-121. http://dx.doi.org/10.1046/j.1525-1497.2000.11218.x

[17] Allibone, A., Oakes, D. and Shannon, H.S. (1981) The Health and Health Care of Doctors. The Journal of the Royal College of General Practitioners, 31, 726-734.

[18] Rivers, P.A. and Bae, S. (1998) Substance Abuse and Dependence in Physicians: Detection and Treatment. Health Manpower Manage, 24, 183-187. http://dx.doi.org/10.1108/09552069810222801

[19] James, H., Handu, S.S., Al Khaja, K.A., Otoom, S. and Sequeira, R.P. (2006) Evaluation of the Knowledge, Attitude and Practice of Self-Medication among First-Year Medical Students. Medical Principles and Practice, 15, $270-275$. http://dx.doi.org/10.1159/000092989

[20] Zafar, S.N., Syed, R., Wagar, S., Zubairi, A.J. and Vagar, T., Shaikh, M., et al. (2008) Self-Medication amongst University Students of Karachi: Prevalence, Knowledge and Attitudes. Journal of Pakistan Medical Association, 58, 214-217.

[21] Sallam, S.A., Khallafallah, N.M., Ibrahim, N.K. and Okasha, A.O. (2009) Pharmacoepidemiological Study of SelfMedication in Adults Attending Pharmacies in Alexandria, Egypt. Eastern Mediterranean Health Journal, 15, 683691.

[22] European Self-Medication Industry (AESGP) (1999) Guiding Principles in Self-Medication.

[23] Dabney, D.A. and Hollinger, R.C. (1999) Illicit Prescription Drug Use among Pharmacists: Evidence of a Paradox of Familiarity. Work and Occupations, 26, 77-106. http://dx.doi.org/10.1177/0730888499026001005

[24] Richman, P.B., Garra, G., Eskin, B., Nashed, A.H. and Cody, R. (2001) Oral Antibiotic Use without Consulting a Physician: A Survey of ED Patients. The American Journal of Emergency Medicine, 19, 57-60. http://dx.doi.org/10.1053/ajem.2001.20035

[25] Hem, E., Stokke, G., Tyssen, R., Grønvold, N.T., Vaglum, P. and Ekeberg, Ø. (2005) Self-Prescribing among Young Norwegian Doctors: A Nine-Year Follow-Up Study of a Nationwide Sample. BMC Medicine, 3, 16. http://dx.doi.org/10.1186/1741-7015-3-16

[26] Tenaw, A. and Tsige, G.M. (2004) Self-Medication Practices of Drug Consumers. Ethiopian Journal of Health Sciences, 14, 1-11.

[27] Sarahroodi, S., Arzi, A., Swalha, A.F. and Ashtranezhad, A. (2010) Antibiotic Self-Medication among Southern Iranian University Students. International Journal of Pharmacology, 6, 48-52. http://dx.doi.org/10.3923/ijp.2010.48.52 